\title{
Effect of silica coating and silane surface treatment on the bond strength of soft denture liner to denture base material
}

\author{
Saadet ATSÜ', Yasemin KESKIN² \\ 1- Professor, Department of Prosthodontics, Kırıkkale University, Faculty of Dentistry, Kırıkkale, Turkey. \\ 2- Professor, Department of Prosthodontics, Ankara University, Faculty of Dentistry, Ankara, Turkey.
}

Corresponding address: Saadet Atsü - Kırıkkale University, Faculty of Dentistry, Department of Prosthodontics - Kurtuluş Mahallesi, 692 Sokak, No:31 71200 - Kırıkkale - Turkey - e-mail: saadetats@yahoo.com - Phone: + 903182244927 - Fax: + 903182250685

Submitted: January 15, 2013 - Modification: May 7, 2013 - Accepted: May 15, 2013

\section{ABSTRACT}

O bjective: This study investigated the effects of different surface treatments on the tensile bond strength of an autopolymerizing silicone denture liner to a denture base material after thermocycling. Material and Methods: Fifty rectangular heat-polymerized acrylic resin (QC-20) specimens consisting of a set of 2 acrylic blocks were used in the tensile test. Specimens were divided into 5 test groups $(n=10)$ according to the bonding surface treatment as follows: Group A, adhesive treatment (Ufi Gel P adhesive) (control); Group S, sandblasting using 50- $\mu \mathrm{m} \mathrm{Al}_{2} \mathrm{O}_{3}$; Group SCSIL, silica coating using 30- $\mu \mathrm{m} \mathrm{Al}_{2} \mathrm{O}_{3}$ modified by silica and silanized with silane agent (CoJet System); Group SCA, silica coating and adhesive application; Group SCSILA, silica coating, silane and adhesive treatment. The 2 PMMA blocks were placed into molds and the soft lining materials (Ufi Gel P) were packed into the space and polymerized. All specimens were thermocycled (5,000 cycles) before the tensile test. Bond strength data were analyzed using 1-way ANOVA and Duncan tests. Fracture surfaces were observed by scanning electron microscopy. X-ray photoelectron spectrometer (XPS) and Fourier Transform Infrared spectrometer (FTIR) analysis were used for the chemical analysis and a profilometer was used for the roughness of the sample surfaces. Results: The highest bond strength test value was observed for Group A (1.35 \pm 0.13$)$; the lowest value was for Group S $(0.28 \pm 0.07)$ and Group SCSIL $(0.34 \pm 0.03)$. Mixed and cohesive type failures were seen in Group A, SCA and SCSILA. Group S and SCSIL showed the least silicone integrations and the roughest surfaces. Conclusion: Sandblasting, silica coating and silane surface treatments of the denture base resin did not increase the bond strength of the silicone based soft liner. However, in this study, the chemical analysis and surface profilometer provided interesting insights about the bonding mechanism between the denture base resin and silicone soft liner.

Key words: Denture bases. Denture liners. Surface properties. Tensile strength.

\section{INTRODUCTION}

The rapid growth of an aging population around the world has increased the use of removable dentures and prompted more studies to develop comfortable conventional acrylic resin dentures. The use of soft liners for relining removable dentures is usually advantageous to avoid stress concentrations and to have a healing effect on the mucosa as well as giving comfort to the patient $9,15,17$. Soft liners have several problems such as loss of softness, colonization by Candida albicans, and bond failure between the liner and denture base. Bond failures also create potential surfaces for bacterial growth, plaque, and calculus formation ${ }^{9,11,15,17-19}$.

Soft lining materials can be divided into two main types: plasticized acrylic resins and silicone elastomers. The silicone soft lining materials generally consist of a hydroxy- or vinyl-terminated polydimethylsiloxane (PDMS) ${ }^{4,5}$. Because of their basic structural differences to polymethylmethacrylate (PMMA) denture base resin, soft liners usually need special adhesives that interact with the surface 
layer of the denture base and soft liner for adequate bond strength ${ }^{4,5}$. The adhesives generally contain a polymeric substance dissolved in a solvent. The polymeric substance can be in one of two forms. First, it can be a reactive molecule. That is, an organo-silane, which usually enhances bonding with its reactive groups. Second, it can be molecules like PMMA dissolved in solvents. In this case, the working mechanism is to increase the wettability of the substrate and to overflow the surface layer with the polymeric ingredients. Although adhesive application onto the base resin surface is frequently used to obtain an adequate bond, it is not enough to prevent debonding between the soft liner and the denture base resin material9,11,15,17-19.

Recently, surface preparation techniques such as the silica coating system was used for the denture base resin surface to increase the bond strength between different resin materials and the denture base $^{8,20}$. The silica coating system based on an air abrasion technique provides ultrafine mechanical retention such as sandblasting with aluminum oxide particles ${ }^{2,16}$. The effect of these systems on the bond strength can be explained by two mechanisms: formation of a topographic pattern that allows micromechanical bonding with the aid of the high-speed surface impact of the alumina particles modified by silica $(30 \mu \mathrm{m})$ and a chemical bond formed between the silica-coated substrate and the resin material2,3,16. In this system, a silane coupling agent is also used for chemical bonding. The general formula of silane is R-Y-SiX3, where $R$ is a nonhydrolyzable organic group, $Y$ is a linker and $X$ is a hydrolyzable group. The nonhydrolyzable functional group (eg, methacrylate) can polymerize with the materials containing $\mathrm{C}=\mathrm{C}$ double bonds (eg, resin composite, soft liners with vinyl group). The hydrolyzable alkoxy groups can react with a hydroxyl group-rich inorganic substrate, such as a silica surface, and form chemical bonds ${ }^{2,14}$. Silica coating systems are applied in many dental practices to increase the bond strength between different materials ${ }^{2,3}$.

Nevertheless, information about silica coating followed by silanization on the bonding of a soft denture liner and denture base material are not available. Therefore, the aim of this study was to test the hypothesis that different applications of silica coating followed by a silanization to the denture base resin increase the bond strength between the silicone based soft denture liner and the heat-cured conventional denture base resin. Since thermal cycling is a factor that can have effects on the durability of materials and it is an important parameter to simulate the oral conditions, the bond strength between the soft denture liner and denture base material was evaluated after thermal cycling. In addition, the present study also aimed to figure out the bonding mechanism between the soft denture liner and denture base resin through surface roughness and chemical composition investigated by the Fourier Transform Infrared spectrometer (FTIR) and X-ray photoelectron spectrometer (XPS) analysis.

\section{MATERIAL AND METHODS}

\section{Tensile test}

In this study, one silicone resilient lining material (Ufi Gel P; VOCO GmbH, Cuxhaven, Germany) and 1 heat-cure acrylic (QC-20, Dentsply Int Inc, Weybridge, Surrey, UK) denture base resin were used. For the tensile test, 100 rectangular specimens, $40 \times 10 \times 10 \mathrm{~mm}\left(10 \times 10 \mathrm{~mm}^{2}\right.$ cross-sectional area), were prepared in a sandwich configuration with a centrally located PMMA portion for each resilient liner. The PMMA specimens were prepared by investing a $3 \mathrm{~mm}$ thick brass spacer in a denture flask. Dyes and spacer machined to the same dimensions were invested in hard but flexible silicone rubber (Zetaplus; Zhermack, Rovigo, Italy) ${ }^{11,17,18}$. Specimens were made by processing resilient denture liners against heat-polymerized PMMA blocks according to the manufacturer's directions. After heat polymerization of the PMMA, the brass spacer and the PMMA resin specimens were removed from the mold. The PMMA resins were trimmed and the surfaces to be bonded were smoothed using \#100, \#400, and \#600 waterproof abrasive papers. The specimens consisting of a set of two acrylic blocks were divided into five groups $(n=10)$ and treated as follows: In Group A, adhesive (Ufi Gel P; VOCO GmbH, Cuxhaven, Germany) was applied to the acrylic base resin surfaces; this group served as a control. In Group S, acrylic base resin surfaces were sandblasted with 50- $\mu \mathrm{m} \mathrm{Al}_{2} \mathrm{O}_{3}$ particles (Koraks; BEGO, Bremen, Germany). In Group SCSIL, acrylic resin surfaces were treated with $30-\mu \mathrm{m} \mathrm{Al}_{2} \mathrm{O}_{3}$ particles modified by silica (CoJet System; 3M ESPE, Seefeld, Germany) using an airborne-particle-abrasion device (CoJet System; 3M ESPE) filled with $30-\mu \mathrm{m}$ silicone-dioxide particles. The abrasive was applied perpendicular to the surface at $0.28 \mathrm{MPa}$ for 15 seconds at a distance of $10 \mathrm{~mm}$, then the surfaces were coated with a silane coupling agent (Silane; 3M ESPE) and allowed to air dry for 5 minutes. In Group SCA, silica coating was applied to acrylic resin surfaces as described for Group SCSIL and then adhesive (Ufi Gel P; VOCO) was applied to the treated base resin surface according to the manufacturer's recommendations. In Group SCSILA, silica coating was applied to the acrylic resin surfaces as described for Group SCSIL then an adhesive (Ufi Gel P; VOCO) and a silane coupling agent (Silane; 3M ESPE) were mixed and this mixture was applied to the treated surfaces and air-thinned for 3 seconds with air spray. The treated PMMA denture base resin specimens were returned 
to the molds. The soft liner (Ufi Gel P; VOCO) was packed into the space made by the brass spacer and polymerized according to the manufacturer's directions. The specimens were removed from the flask, and waste materials were trimmed with a sharp knife. All specimens were thermocycled (5000 cycles) between baths of $5^{\circ}$ and $55^{\circ} \mathrm{C}$ with a transfer time of 30 seconds and a dwell time of 30 seconds. Then the specimens were stored for 24 hours in water at $37^{\circ} \mathrm{C}$ before the bond test. The tensile bond strength was tested with a universal testing machine (Lloyd-LRX; Lloyd Instruments Ltd, Fareham, UK) at a crosshead speed of $0.5 \mathrm{~mm} / \mathrm{min}$ using material testing software (Nexygen version 2.0; Lloyd Instruments). A 1-way analysis of variance (ANOVA) and the Duncan test were used to assess the significance of differences in the tensile bond strength between the groups, with the level of significance set at $p<0.05$.

After the surface treatment, one additional specimen from each group was coated with goldpalladium alloy using a sputter-coating technique (Hummer VII; Anatech Ltd, Alexandria, Va) and examined by scanning electron microscopy (SEM) (JSM-5600 Scanning Microscope; JEOL Ltd, Tokyo, Japan) at $\times 500$ magnification to observe the topographic patterns.

\section{Mode of failure}

The debonded specimen surfaces were examined by the same observer with a stereomicroscope (Leica MZ 12; Leica Microsystems, Bensheim, Germany) at $\times 40$ magnification to assess the mode of failure. Adhesive and/or cohesive failure of bonding could occur at three locations: (1) adhesive failure at the interface between the denture base and soft liner; (2) cohesive failure within the denture base or within the soft liner; and (3) adhesive and cohesive failure at the same site, or a mixed failure ${ }^{3}$.
FTIR analysis

A Bruker Vertex $70 \mathrm{~V}$ Fourier Transform Infrared Spectrometer (FTIR) (Bruker Optics Inc., Ettlingen, Germany) was used with a Pike Miracle Attenuated Total Reflectance (ATR) to identify the functional groups of material. FTIR spectra of the groups and untreated surface of PMMA sample $(5 \times 5 \times 1.5 \mathrm{~mm})$ were obtained by placing the surface to be analyzed on the diamond crystal. FTIR spectrum of adhesive was also taken by placing a few drops on a potassium bromide pellet ${ }^{4,5}$.

\section{XPS analysis}

An X-ray Photoelectron Spectroscopy system (XPS) (Sage 150, Specs GmbH, Berlin, Germany) was used to obtain information about the composition and the chemical bonding of elements found in the surface region of untreated and treated samples. Specimens of $10 \mathrm{~mm}$ diameter and $2 \mathrm{~mm}$ thick were prepared for the analysis ${ }^{5}$. The specimens were investigated by XPS survey spectra with 5-6 nm sampling depth, $100 \mu$ spot size, $50.4 \mathrm{~W}$ power for carbon, oxygen and silicone elements.

\section{Surface roughness analysis}

Five disc-shaped samples $(10 \mathrm{~mm}$ diameter and $2 \mathrm{~mm}$ thick) of each group were prepared to evaluate the surface roughness. A Perthometer M2 (Mahr, Germany) device was used. The mean surface roughness $(\mathrm{Ra})$ values of each group sample were obtained through the measurements 3 times, made by one observer ${ }^{22}$. Results were evaluated with 1-way ANOVA and the Duncan tests.

\section{RESULTS}

The results of the 1-way ANOVA revealed that the bond strengths differed significantly between the groups $(p<0.001$, Sum of squares $8.37, d f=49$, $\mathrm{F}=146.89$ ). The mean tensile bond strength values

Table 1- The Group bond strength values (MPa) and failure mode $(n=10)$

\begin{tabular}{|c|c|c|c|c|}
\hline \multirow[t]{2}{*}{ Groups } & \multirow[t]{2}{*}{ Mean and SD } & \multicolumn{3}{|c|}{ Failure mode } \\
\hline & & Adhesive & Cohesive & Mixed \\
\hline Group A & $1.35 \pm 0.13^{a}$ & & 9 & 1 \\
\hline Group S & $0.28 \pm 0.07^{c}$ & 9 & & 1 \\
\hline Group SCSIL & $0.34 \pm 0.03^{c}$ & 9 & & 1 \\
\hline Group SCA & $0.91 \pm 0.17^{\mathrm{b}}$ & 2 & 3 & 5 \\
\hline Group SCSILA & $1.01 \pm 0.13^{b}$ & 2 & 4 & 4 \\
\hline
\end{tabular}

Same superscripted letters indicate no significant difference $(p<0.001)$

SD: Standard deviation.

Group A: Adhesive treatment; Group S: Sandblasting

Group SCSIL: Silica coating and silanized with a silane coupling agent (CoJet System)

Group SCA: Silica coating and adhesive application

Group SCSILA: Silica coating, silane and adhesive treatment 
and standard deviations of the groups and numbers of failure modes for each group are listed in Table 1. The highest bond strength was obtained with the adhesive application (Group A). The lowest bond strengths were obtained without adhesive application specimens (Group S and Group SCSIL). The bond strength values were significantly higher for Group SCA and SCILA specimens than for Group S and SCSIL specimens.

Scanning electron microscopy images of differently treated acrylic surfaces are shown in Figure 1. The topographic patterns were similar for Group S and Group SCSIL. These groups showed a rougher surface than the others. The topographic patterns were also
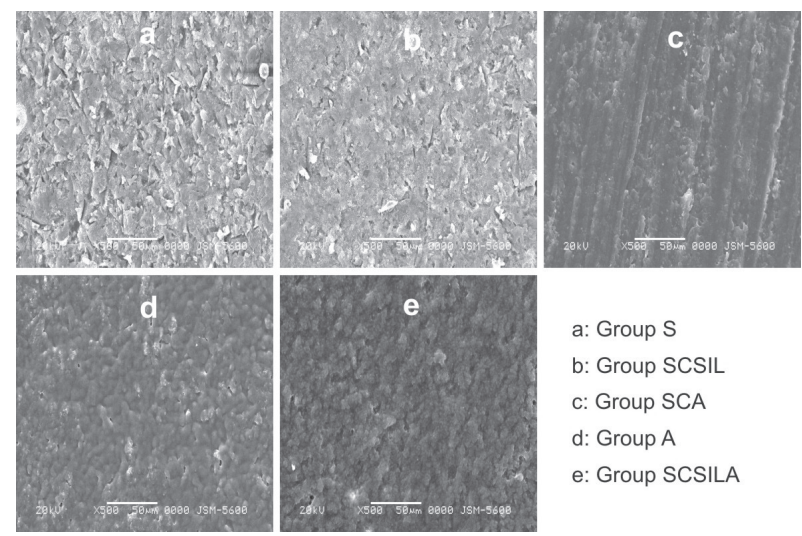

a: Group S

b: Group SCSIL

c: Group SCA

d: Group A

e: Group SCSILA

Figure 1- Scanning electron microscopy images of the experimental groups (original magnification $\times 500$ ). Note difference in surface texture between images, indicating that the sandblasted (Group S) and silica coated followed by the silanization (Group SCSIL) groups have rougher surfaces than the other groups similar for Group A, Group SCA and Group SCSILA, which appeared to be affected by the treatment of adhesive. The images indicate that the adhesive infiltrated the roughened structures and led to more smooth and homogeneous surfaces than the others.

FTIR peaks (Wavenumber - $\mathrm{cm}^{-1}$ ) of untreated PMMA, soft liner, adhesive and experimental groups are listed in Figure 2. Figure 3 shows the FTIR spectra of untreated PMMA and experimental groups. FTIR analysis showed that Group $\mathrm{S}$ had no functional siloxane $(\mathrm{Si}-\mathrm{O}-\mathrm{Si})$ and vinyl $\left(\mathrm{CH}_{2}=\mathrm{CH}\right)$ group. The strong peak of vinyl at $988-904 \mathrm{~cm}^{-1}$ was seen only in the adhesive treated groups (Group A, SCA and SCSILA). Height of trimethoxysilane $\left(\mathrm{Si}-\mathrm{OCH}_{3}\right)$ peaks at $1270-1260 \mathrm{~cm}^{-1}$ and siloxane peaks ( $\mathrm{Si}-\mathrm{O}-\mathrm{Si}$ ) at 1077-1008 $\mathrm{cm}^{-1}$ were shorter in untreated PMMA, Groups S and SCSIL than the other experimental groups (Figure 3 ). Figure 4 shows the FTIR spectrum of the soft liner and the adhesive. FTIR analysis indicated that soft liner had strong $\mathrm{Si}-\mathrm{O}-\mathrm{Si}$ (siloxane) peak at 1070, 1008, and $\mathrm{CH}_{2}=\mathrm{CH}$ (vinyl) peak at 864,786 . The adhesive has strong Si-O-Si (siloxane) peak at $1091 \mathrm{~cm}^{-1}, \mathrm{C}=\mathrm{O}$ (carbonyl) peak at 1731 $\mathrm{cm}-1$ and $\mathrm{CH}_{2}=\mathrm{CH}$ (vinyl group) at $907 \mathrm{~cm}^{-1}$. C-H asymmetric vibration stretch band occurred at 2992-2951 cm-1 which indicates $\mathrm{CH}_{3}$ (methyl), $\mathrm{CH}_{2}$ (methylene), $\mathrm{CH}$ (methyne) in the adhesive.

Quantitative values of carbon (C), oxygen (O), and silicone ( $\mathrm{Si}$ ) obtained from the XPS analysis on the surface region of untreated and treated samples were as follows: Untreated PMMA 66.2\% C, 25.6\% O, 8.2\% Si; Group A 55.1\% C, 33.6\% O, 11.3\% Si; Group S 39.8\% C, 51.9\% O, 8.3\% Si; Group SCSIL $36.9 \%$ C, $53.1 \%$ O, $10 \%$ Si; Group SCA 53.9\% C, $34.4 \%$ O, $11.7 \%$ Si; Group SCSILA $54.4 \%$ C, 32.5\%

Figure 2- Transmittance FTIR peaks $\left(\mathrm{cm}^{-1}\right)$ and group/structure of the untreated PMMA, the soft liner, the adhesive and the experimental groups

\begin{tabular}{|c|c|c|c|c|c|c|c|c|}
\hline \multirow[t]{2}{*}{ Group/Structure } & \multicolumn{8}{|c|}{ FTIR Peaks (Wavenumber) } \\
\hline & PMMA & $\begin{array}{c}\text { Soft } \\
\text { liners }\end{array}$ & Adhesive & Group A & Group S & $\begin{array}{l}\text { Group } \\
\text { SCSIL }\end{array}$ & $\begin{array}{c}\text { Group } \\
\text { SCA }\end{array}$ & $\begin{array}{l}\text { Group } \\
\text { SCSILA }\end{array}$ \\
\hline $\begin{array}{c}\text { Methyl }\left(\mathrm{CH}_{3}\right) \text {, } \\
\text { Methyne }(\mathrm{CH}) \\
\text { Methylene }\left(\mathrm{CH}_{2}\right)\end{array}$ & $\begin{array}{l}2991 \\
2949\end{array}$ & 2963 & $\begin{array}{l}2992 \\
2951\end{array}$ & $\begin{array}{l}2991 \\
2949\end{array}$ & $\begin{array}{l}2991 \\
2949\end{array}$ & $\begin{array}{l}2949 \\
2918\end{array}$ & $\begin{array}{l}2990 \\
2951\end{array}$ & $\begin{array}{l}2951 \\
2929\end{array}$ \\
\hline Carbonyl $(\mathrm{C}=\mathrm{O})$ & 1723 & & 1731 & 1725 & 1724 & 1724 & 1727 & 1725 \\
\hline Methylsilylidyne $\left(\mathrm{Si} \mathrm{CH}_{3}\right)$ & 1270 & & 1261 & 1270 & 1268 & & 1270 & 1260 \\
\hline Trimethoxysilane $\left(\mathrm{Si}-\mathrm{OCH}_{3}\right)$ & 1190 & & 1191 & 1190 & 1190 & & 1190 & 1190 \\
\hline $\mathrm{C}-\mathrm{O}-\mathrm{C}$ & 1144 & & 1147 & 1138 & 1143 & & & \\
\hline Siloxane (Si-O-Si) & & $\begin{array}{l}1070 \\
1008 \\
\end{array}$ & 1091 & 1064 & & 1077 & 1041 & 1074 \\
\hline Vinyl $\left(\mathrm{CH}_{2}=\mathrm{CH}\right)$ & 987 & $\begin{array}{l}864 \\
786\end{array}$ & 906 & $\begin{array}{l}988 \\
907\end{array}$ & & & 904 & 904 \\
\hline
\end{tabular}

FTIR=Fourier Transform Infrared spectrometer

PMMA=polymethylmethacrylate 


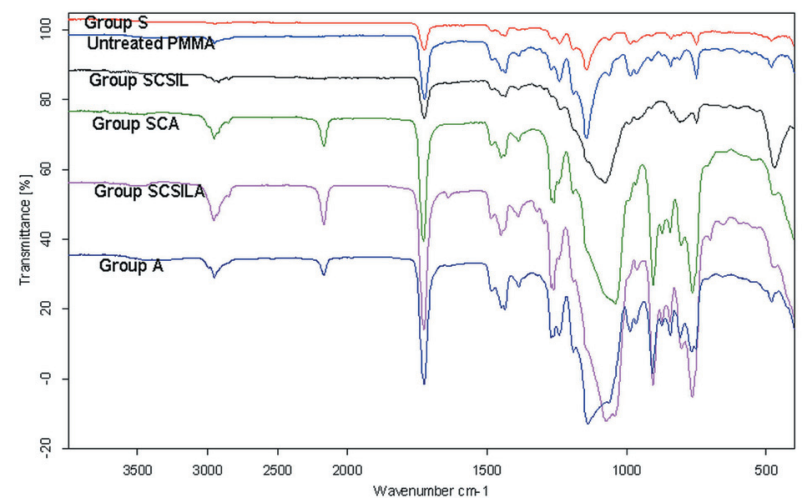

Figure 3- Fourier Transform Infrared spectrometer (FTIR) spectra of the untreated polymethylmethacrylate (PMMA) and the experimental groups
Table 2- Surface roughness means and standard deviations of the groups

\begin{tabular}{ccc}
\hline Groups & Ra $(\mu \mathrm{m})$ & SD \\
\hline Untreated & $0.68^{\mathrm{a}, \mathrm{b}}$ & 0.01 \\
Group A & $0.51^{\mathrm{a}}$ & 0.01 \\
Group S & $3.39^{\mathrm{d}}$ & 0.3 \\
Group SCSIL & $1.31^{\mathrm{c}}$ & 0.01 \\
Group SCA & $0.76^{\mathrm{b}}$ & 0.01 \\
Group SCSILA & $0.75^{\mathrm{b}}$ & 0.03 \\
\hline
\end{tabular}

Same superscripted letters indicate no significant difference $(p<0.05)$
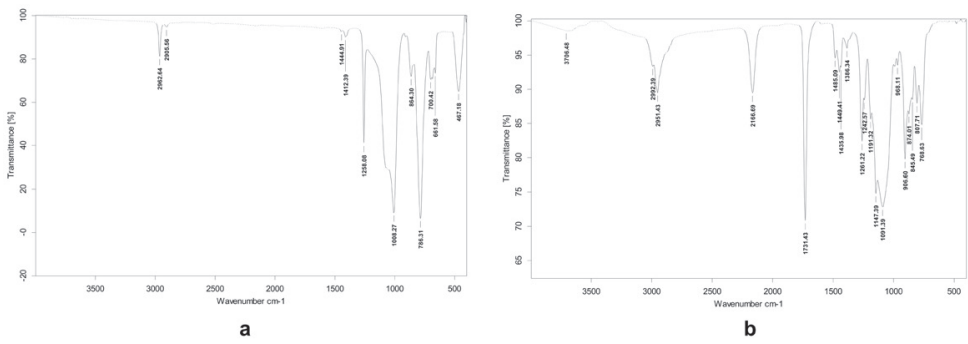

Figure 4- Fourier Transform Infrared spectrometer (FTIR) spectra of the adhesive (a) and the soft liners (b)
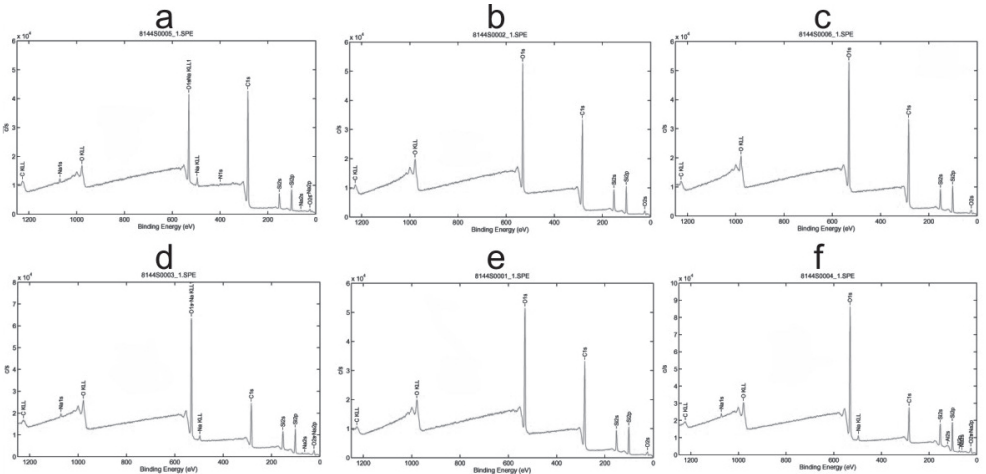

Figure 5- X-ray photoelectron spectrometer (XPS) spectra for the surfaces of untreated polymethylmethacrylate (a), Group A (b), Group S (c), Group SCSIL (d), Group SCA (e) and Group SCSILA (f)

O, $13.1 \%$ Si. The most significant change occurred in Group S and SCSIL compared to the non-treated group based resin surface. The carbon content decreased from $66 \%$ to $37-40 \%$ and the oxygen content increased from $26 \%$ to $52-53 \%$. Group A, Group SCA and Group SCSILA showed no significant difference between each other. The lowest silicone concentration was observed on the untreated base resin surface and $S$ groups. The XPS spectra for the surfaces of untreated PMMA and experimental groups are shown in Figure 5.

The surface roughness of the groups and the standard deviation are shown in Table 2. Statistically significant differences ( $p<0.001$, Sum of squares 17.9, $d f=5, F=228.3$ ) were found between the groups. The roughest surfaces were observed in Group S. Although no significant differences were observed between Group A, SCA and SCSILA, the smoothest surfaces were found in Group A.

\section{DISCUSSION}

Denture resilient lining materials have become important in dental prosthetic treatment. However, one of the most serious problems is failure of the bond between the soft denture liner and the denture base resins ${ }^{9,11,15,17-19}$. In this study, to increase the bond strength of the soft denture liner to the denture base materials, different surface conditioning methods such as silica coating, silica coating followed by 
silanization, adhesive and adhesive/silane mixture were applied to the base resin surface. The hypothesis of this study was that the bonding could be increased by the application of a silica coating, silane and/or adhesive/silane coupling agent mixture. The results of the study do not confirm this hypothesis. Although, Group A (adhesive treatment), SCSILA (silica coating/ silane/adhesive treatment) and SCA (silica coating/ adhesive treatment) exceeded a clinically acceptable and adequate bond strength between the soft liner and denture base ${ }^{10,11,17,18}$, the highest bond strengths were found in Group A. The results of the tensile bond tests were also consistent with the failure modes. Groups S (sandblasting) and SCSIL (silica coating/ silane treatment) showed the lowest bond strengths and adhesive type failures, whereas Group A, which had the highest bond strengths, showed mixed and cohesive type failures.

Tensile, shear and peel tests are widely accepted methods for evaluating the bond strength of soft denture liners to the denture base. In line with the previous studies ${ }^{11,17,18}$, tensile tests were used to determine the bond strength between the soft denture liner and denture base resin. Although the peel test is believed to be the best simulation test of the clinical condition for soft lining materials, the results show that peel tests have a higher probability of cohesive failures in the soft materials and this test can be influenced by the thickness of materials. The shear bond strength is also affected by the deformation rates of the materials. In the tensile bond test, the area involved as a whole is stressed simultaneously and no allowance is made for the deformation of the materials. Although the tensile test does not simulate clinically exposed forces of lining material, it has been considered as a good method ${ }^{4,15}$.

Thermocycling is a common way to more closely simulate the oral condition. This treatment allows repeated expansion and contraction between the soft denture liner and denture base material and results in stress at the bonding interface and thermal volumetric changes. It has been implicated that thermal cycling stress was one of the factors degrading the bond between the silicone liners and denture base resin. Like the previous studies ${ }^{2,12}$, the present study used thermocycling only with the purpose of simulating the oral environment. Therefore bond strengths before and after thermocycling have not been compared. For the thermocycling procedure, a temperature range from $5^{\circ} \mathrm{C}$ to $55^{\circ} \mathrm{C}$ (according to the temperatures that exist intraorally) and 5000 thermal cycles (simulates total prosthesis use in approximately 5 years) were chosen in the present study ${ }^{4,12,18}$.

In addition to the bond strength test, the chemical and roughness analyses of surfaces provided interesting insights about the nature of the bond between the denture base resin and silicone soft liner. Chemical compositions between the soft liner and base resin were investigated by FTIR and XPS analysis. While the FTIR analysis was used to identify the functional groups of material, the XPS analysis was used to obtain information about the composition and the chemical bonding of elements found in a surface region. FTIR analyses of the adhesive and soft liner indicated that the adhesive had the siloxane $\left(1091 \mathrm{~cm}^{-1}\right)$, methyl (2992-2951 $\mathrm{cm}^{-1}$ ) and vinyl (907 $\mathrm{cm}^{-1}$ ) functional groups (Figure 4 ). The main compound of the silicone soft liner has been siloxane polymer with vinyl groups. These findings were consistent with the previous studies ${ }^{4,5}$. These studies revealed that silicone soft liner was a form of polydimethylsiloxane polymer bearing vinyl end groups and the adhesive of the soft liner was 3-methacryloxypropyltrimethoxy silane ${ }^{4,5}$.

In the present study, the FTIR analysis showed that the adhesive and silane treated groups (Group A, SCA, SCSILA and SCSIL) had the trimethoxysilane $\left(\mathrm{Si}-\mathrm{OCH}_{3}\right)$ group which indicated the silane grafting and siloxane (Si-O-Si) group which was a result of the silane crosslinking during the grafting process (Figure 3$)^{5,7,13,21}$. The height of trimethoxysilane and siloxane peaks could be used as the corresponding value to compare the silane grafting efficiency ${ }^{13,21}$. When the height of trimethoxysilane and silane peaks among the experimental group and untreated PMMA were compared, the shortest peaks were observed in Group S and untreated PMMA. Besides, the XPS analysis results have shown an increasing number of $\mathrm{Si}$ (in atomic mol percent) in the adhesive and silane treated group. When the tensile bond strength results were combined with those of the FTIR and XPS analysis, special silane (with vinyl and methacrylate groups) requirement could be stressed for better bonding between the soft liner and PMMA.

In light of these findings, it is concluded that PMMA, which has a double bond terminated by other active centers, is compatible with the methacrylate end of the adhesive. The methacrylate end of the adhesive could be bound chemically to the PMMA resin while the silicone ends with the soft lining material. Vinyl groups of adhesives, PMMA and soft lining material cause additional reactions. On the other hand, the Si groups from the silicone soft lining material reacted with the methoxy-Si groups from the adhesive which forms silane. As a result, the adhesive could bond the soft lining material to the PMMA resin.

In this study, the surface roughnesses were also investigated. It was found that the roughest surface was observed in the sandblasted group (Group S) and then silica-coated followed by the silanization group (Group SCSIL) which can also be seen on the SEM images (Figure 1). Interestingly, the lowest bond strengths were also observed in these groups. The results of this study are consistent with the previous 
studies ${ }^{1,6}$ which found that sandblasting of base resin surface decreased the bond strength between the soft liners and base resin. Lower bond strength can be explained by stresses that occurred after sandblasting at the interface ${ }^{1}$ and the reduced ability of the soft lining material to penetrate into the irregularities of the PMMA ${ }^{6}$.

A review of the literature indicated that two previous studies 8,20 used silica coating and silane surface treatment on the denture base resin surface to increase the bond strength of the gingival shade composite resin and the autopolymerizing repair resin. It was found that the silica coating system was effective in improving the bond strength. However, in this study, the surface treatment method (silica coating followed by silanization) of the denture base resin showed no improvement in the bond strength between the soft liner materials and denture base resin. These results may be attributed to the fact that silica coating systems lead the roughness surfaces and irregularities created by $30-\mu \mathrm{m}$ silicon-dioxide particles may not be sufficient to allow flow of the soft resilient lining material into the base resin'.

In future studies, the effects of different silane agents could be examined.

\section{CONCLUSIONS}

Within the limitation of this study, the following conclusions can be drawn.

1- Surface treatment methods (sandblasting, silica coating and silica coating followed by silanization) did not improve the bond strength of the silicone based soft denture liner (Ufi gel $\mathrm{P}$ ) to the heat-cured based resin (QC-20).

2- The highest bond strength between the denture base resin and the silicone based soft denture liner was obtained by adhesive application to the base resin.

3- FTIR and XPS analysis showed increased siloxane ( $\mathrm{Si}-\mathrm{O}-\mathrm{Si}$ ) groups in the adhesive treated groups (Group A, SCA, SCSILA) and these groups had also higher bond strengths compared to the others.

4- Surface roughness created by silica coating and sandblasting was not suitable for the bonding mechanism between the silicone soft lining material and denture base resin. The groups had a rougher surface (Group S and SCSIL) demonstrating a lower bond strength compared to the other groups.

\section{ACKNOWLEDGEMENT}

The authors would like to thank Assoc.Prof. Muhammet Işıkalan from Kübtal for interpreting the chemical analysis.

\section{REFERENCES}

1- Amin WM, Fletcher AM, Ritchie GM. The nature of the interface between polymethyl methacrylate denture base materials and soft lining materials. J Dent. 1981;9:336-46.

2- Atsü SS, Gelgör IE, Sahin V. Effects of silica coating and silane surface conditioning on the bond strength of metal and ceramic brackets to enamel. Angle Orthod. 2006;76:857-62.

3- Atsü SS, Kilicarslan MA, Kucukesmen HC, Aka PS. Effect of zirconium-oxide ceramic surface treatments on the bond strength to adhesive resin. J Prosthet Dent. 2006;95:430-6.

4- Demir H, Dogan A, Dogan OM, Keskin S, Bolayir G, Soygun K. Peel bond strength of two silicone soft liners to a heat-cured denture base resin. J Adhes Dent. 2011;13(6):579-84.

5- Doğan OM, Keskin S, Doğan A, Ataman H, Usanmaz A. Structureproperty relation of a soft liner material used in denture applications. Dent Mater J. 2007;26:329-34.

6- Jacobsen NL, Mitchell DL, Johnson DL, Holt RA. Lased and sandblasted denture base surface preparations affecting resilient liner bonding. J Prosthet Dent. 1997;78:153-8.

7- Jiao C, Wang Z, Gui Z, Hu Y. Silane grafting and crosslinking of ethylene-octene copolymer. Eur Polym J. 2005;41:1204-11.

8- Katsumata Y, Hojo S, Hamano N, Watanabe T, Yamaguchi H, Okada $S$, et al. Bonding strength of autopolymerizing resin to nylon denture base polymer. Dent Mater J. 2009;28:409-18.

9- Kawano F, Dootz ER, Koran A $3^{\text {rd }}$, Craig RG. Comparison of bond strength of six soft denture liners to denture base resin. J Prosthet Dent. 1992;68:368-71.

10- Khan Z, Martin J, Collard S. Adhesion characteristics of visible light-cured denture base material bonded to resilient lining materials. J Prosthet Dent. 1989;62:196-200.

11- Kulak-Ozkan Y, Sertgoz A, Gedik H. Effect of thermocycling on tensile bond strength of six silicone-based, resilient denture liners. J Prosthet Dent. 2003;89:303-10.

12- León BL, Del Bel Cury AA, Rodrigues Garcia RC Water sorption, solubility, and tensile bond strength of resilient denture lining materials polymerized by different methods after thermal cycling. J Prosthet Dent. 2005;93:282-7.

13- Morshedian J, Hoseinpour PM, Azizi H, Parvizzad R. Effect of polymer structure and additives on silane grafting of polyethylene. Express Polym Lett. 2009;3:105-15.

14- Mulik S, Sotiriou-Leventis C, Leventis N. Adhesion enhancement of polymeric films on glass surfaces by a silane derivative of azobisisobutyroni trile (AIBN). Polymer Preprints. 2008;49:498-9. 15- Mutluay MM, Ruyter IE. Evaluation of bond strength of soft relining materials to denture base polymers. Dent Mater. 2007;23:1373-81.

16- Peutzfeldt A, Asmussen E. Silicoating: evaluation of a new method of bonding composite resin to metal. Scand J Dent Res. 1988;96:171-6.

17- Pinto JR, Mesquita MF, Henriques GE, Arruda Nóbilo MA. Effect of thermocycling on bond strength and elasticity of 4 long-term soft denture liners. J Prosthet Dent. 2002;88:516-21.

18- Pinto JR, Mesquita MF, Nóbilo MA, Henriques GE. Evaluation of varying amounts of thermal cycling on bond strength and permanent deformation of two resilient denture liners. J Prosthet Dent. 2004; $92: 288-93$.

19- Polyzois GL, Frangou MJ. Influence of curing method, sealer, and water storage on the hardness of a soft lining material over time. J Prosthodont. 2001;10:42-5.

20- Shimizu H, Kawaguchi T, Yoshida K, Tsue F, Takahashi Y. Effect of surface preparation on the failure load of a highly filled composite resin bonded to a denture base resin. J Prosthodont. 2009;18:684-7. 21- Wong WK, Varrall DC. Role of molecular structure on the silane cross-linking of polyethylene: the importance of resin molecular structure change during silane grafting. Polymer. 1994;35:5447-52. 22- Yilmaz K, Ozkan P. Profilometer evaluation of the effect of various polishing methods on the surface roughness in dental ceramics of different structures subjected to repeated firings. Quintessence Int. 2010;41:125-31. 